\title{
Voltage Clamping Circuits for Large Voltage Step-Down Coupled Inductor Converters
}

\author{
Richard Pollock \\ University of Strathclyde 16 Richmond St, Glasgow G1 1XQ, UK. \\ richard.pollock@strath.ac.uk
}

\begin{abstract}
Water desalination processes require power converters with large voltage step-down ratios and high efficiencies. Coupled inductor (tappedinductor) circuits can achieve this where the whole inductor carries current during one switch state but only part of the inductor carries current during the second switch state. The switch state change results in excessive switch voltages due coupling leakage. To protect the switching device, a novel voltage clamp is presented which improves the overall efficiency of the switching circuit and recovers otherwise wasted energy. It requires no closed-loop control. For higher power levels, an asymmetric half-bridge coupledinductor buck converter circuit, which offers switch protection without a snubber, is presented. The circuit is shown to offer reduced switching losses despite having two switching components in the high-voltage forward conduction path.
\end{abstract}

Keywords - asymmetrical half-bridge coupledinductor buck converter, buck converter, coupledinductor buck converter, reversible buck converter, tapped-inductor buck converter.

\section{INTRODUCTION}

Various methods, such as reverse osmosis, and multistage flash distillation, are used for water desalination. This research focuses on capacitive deionization (CDI) water desalination. The method requires a voltage less than 1.5V [1]: the Nernst voltage of water. For a saline solution of 2000 parts per million, CDI uses $66 \%$ less energy than reverse osmosis, which is the next best alternative method [2]. CDI requires the charging and discharging of a capacitor-like cell. This research investigates circuits that can achieve bidirectional current flow and a low-voltage output.

This low-voltage would typically be derived from a conventional domestic or industrial rectified $A C$ supply. The coupled-inductor buck converter has been proposed as a circuit that can achieve the large stepdown ratios desired: typically, in the range of 600:1. Circuits with large step-down ratios require protection on the main switch due to the leakage energy associated with the coupled inductor. Two such variants of the coupled-inductor buck converter with switch protection are presented. In this research, the merits of a half-bridge circuit with two switches rated for full current, and a single-ended circuit requiring only one switch rated for the full primary current, but requiring a voltage clamp circuit to protect the primary switching device against a potential over-voltage while allowing the voltage to rise highly enough to enable efficient transfer of the stored energy to the secondary winding, are compared.

The paper is organized as follows. Section 3 documents derivation of the voltage transfer ratio of the coupled inductor circuit and shows why it is suitable for large voltage step-down ratios such as required in desalination. The new asymmetric halfbridge coupled-inductor buck converter is introduced in Section 4. Section 5 describes the single-ended magnetically-coupled converter, and introduces a voltage clamp with energy recovery to manage the leakage energy. Test results at a range of clamp voltages are presented. Section 6 compares the test results for the new asymmetric half-bridge with those for the voltage-clamped single-ended converter. Finally, the results are discussed in relation to the desalination process.

\section{COUPLED-INDUCTOR BUCK CONVERTER}

Power converters for water desalination processes can require step-down ratios in the order of $600: 1$. This arises where the input voltage is derived from a rectified three-phase supply at typically $600 \mathrm{~V}$, and a voltage of less than $1.5 \mathrm{~V}$ is required to electrolyze a solution of impure water.

The coupled-inductor converter, Fig. 1, is a version of the buck converter which has a split or tapped inductor. In one circuit switching state, the whole inductor conducts the current. In the second circuit switching state, only part of the inductor conducts. 


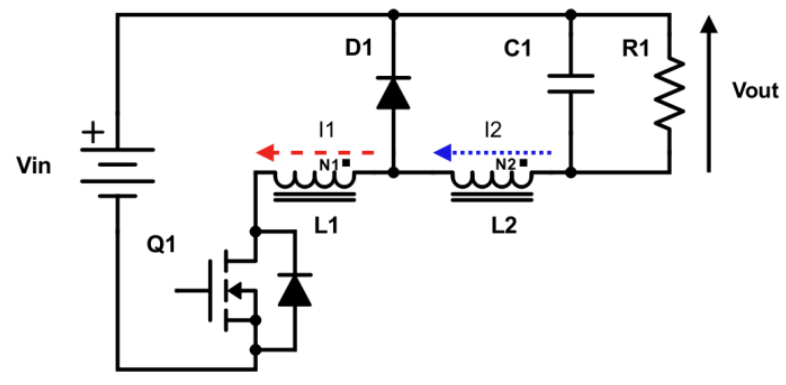

Fig .1 (a) Coupled-inductor buck converter [3].

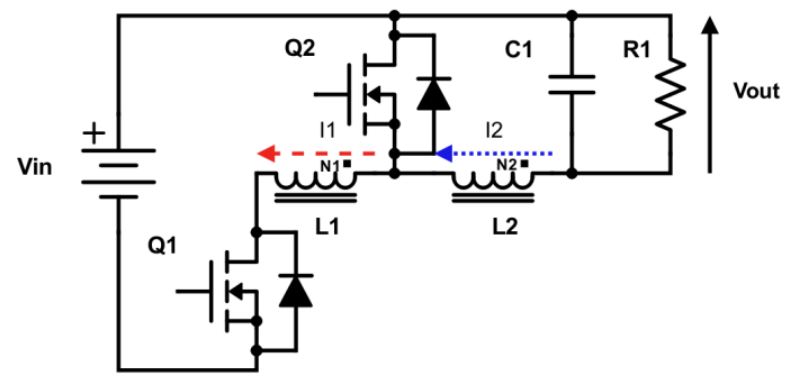

Fig .1 (b) Reversible coupled-inductor buck converter with synchronous rectification [3].

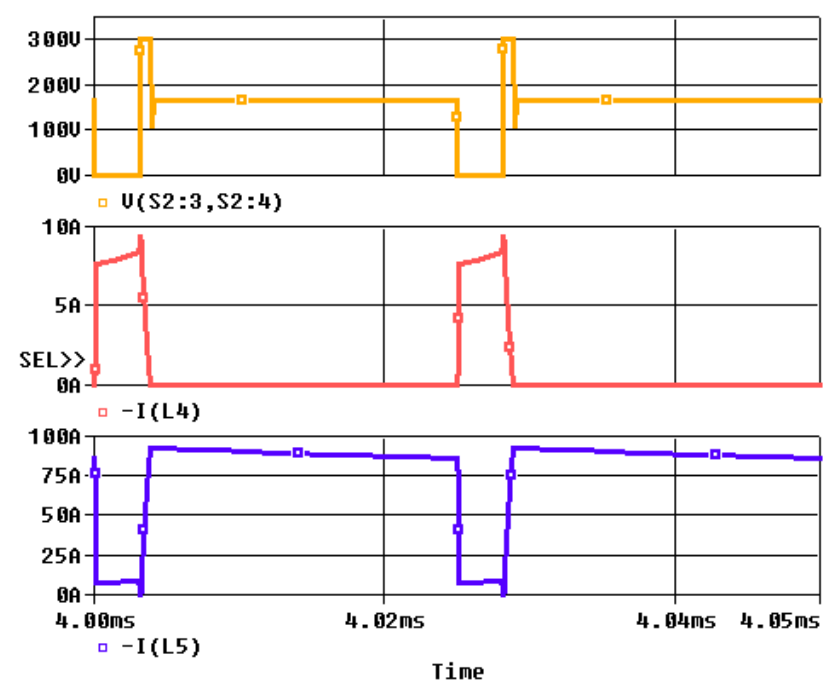

Fig .1 (c) Coupled-inductor buck converter simulation.

The input voltage Vin is converted to a significantly lower output voltage $V_{\text {out }}$. When the main single switch Q1 is turned on, current flows through the load R1 and the series-connected coupled inductor L1 with N1 primary turns and $\mathrm{N}_{2}$ secondary turns. During this time the flux in the core of the coupled-inductor increases as does the energy stored. Unlike the flyback converter [4], the coupled-inductor circuit's energy is provided to the load R1 during the on-time of Q1. The energy stored is the combined energy storage of the coupled inductors L1 and L2. When switch Q1 is turned off, all the stored energy becomes associated with the inductor L2 with turns $N_{2}$. The current in L2 and therefore the load current (via diode D1) decrease. The stored energy decreases whilst energy is delivered to the load.

L1 and L2 will never be 100\% coupled and energy associated with the leakage inductance between these windings must be managed correctly when Q1 turns off. In single-switch converters such as those shown in Fig. 1 the energy associated with the leakage inductance causes the voltage across the primary side switching device Q1 to increase when it is turned off.

In the coupled inductor, the voltage across L1 has to reverse and exceed the referred voltage of the secondary before energy can start to transfer to the secondary winding. In the single-ended converter the voltage across the primary switching device increases to a level in excess of the DC supply voltage. Due to the leakage inductance the voltage across Q1 has to rise further to absorb the additional energy stored in the leakage inductance which is not transferred to the secondary.

Currents $I_{1}$ in L1 and $I_{2}$ in L2 are shown in the second and third plots of the simulations in Fig.1(c), where the inductors have $97.5 \%$ coupling. The voltage across the main switch Q1 rises to 300V.

\section{VOLTAGE TRANSFER EQUATIONS OF COUPLED-INDUCTOR BUCK CONVERTER}

The coupled-inductor buck circuit in Fig. 1 can be analyzed similarly to the standard buck converter circuit.

When the main switch $Q 1$ conducts with duty ratio, $\delta$ :

$V_{\text {in }}-V_{\text {out }}=\frac{L_{\text {total }}}{\delta T_{s}}\left(I_{1_{\max }}-I_{1_{\text {min }}}\right)$

When the main switch Q1 turns off:

$V_{\text {out }}=\frac{L_{2}}{(1-\delta) T_{s}}\left(I_{2_{\max }}-I_{2_{\min }}\right)$

The secondary inductance with $N_{2}$ turns can be expressed as a fraction of the total inductance $\left(L_{\text {total }}=L_{1}+L_{2}\right)$ :

$L_{2}=\left(\frac{N_{2}}{N_{1}+N_{2}}\right)^{2} L_{\text {total }}$

The MMF in the inductor must be continuous in either side of the switching boundary. Therefore: 
$\left(N_{1}+N_{2}\right) I_{1_{\text {max }}}=N_{2} I_{2 \max }$

Using (3) and (4) the output voltage can be expressed as:

$$
\begin{aligned}
V_{\text {out }}=\frac{\left(\frac{N_{2}}{N_{1}+N_{2}}\right)^{2} L_{\text {total }}}{(1-\delta) T_{S}} \times \frac{N_{1}+N_{2}}{N_{2}}\left(I_{1_{\text {max }}}-I_{1_{\text {min }}}\right) \\
=\frac{\frac{N_{2}}{N_{1}+N_{2}} L_{\text {total }}\left(I_{1_{\text {max }}}-I_{1_{\text {min }}}\right)}{(1-\delta) T_{S}}
\end{aligned}
$$

Combining (1) and (5), and eliminating currents and period $T_{s}$ :

$\frac{V_{\text {out }}}{V_{\text {in }}}=\frac{\delta N_{2}}{N_{2}+(1-\delta) N_{1}}$

The voltage transfer function of the coupled-inductor buck converter therefore has the benefit of the inductor turns ratio in addition to the duty ratio $\delta$ of the main switch Q1 to achieve large step-down voltage ratios (c.f. similar to $A C$ autotransformer action).

\section{ASYMMETRIC HALF-BRIDGE COUPLED- INDUCTOR CONVERTER}

The converter shown in Fig. 2 is the asymmetric halfbridge version of the circuit shown in Fig.1(b). Two switches; Q1 and Q2, are used to apply the input voltage to the coupled inductor and output circuit. When Q1 and Q2 turn off, the current transfers into clamping diodes D1 and D2. This effectively changes the potential difference across the coupled inductor from $V_{\text {in }}$ to $-V_{\text {in }}$ which creates an effective voltage swing of $2 V_{i n}$. Thus, the current transfer time is quicker than for the conventional coupled-inductor buck converter in Fig. 1 (b). The current in primary winding L1 is forced to zero and the secondary current can flow in the synchronous rectifier Q3. Both switches Q1 and Q2 are protected from the effects of leakage inductance by their associated diodes, D1 and D2, which clamp them to $V_{i n}$ for Q1 and GND for Q2.

A coupled-inductor circuit driven by an asymmetric half-bridge uses the supply protect the main switching devices from over-voltage. Although the clamping circuit uses two switches and two diodes, the devices are all rated close to the input supply voltage. The additional switch is added just as in the two switch flyback converter [5], [6].

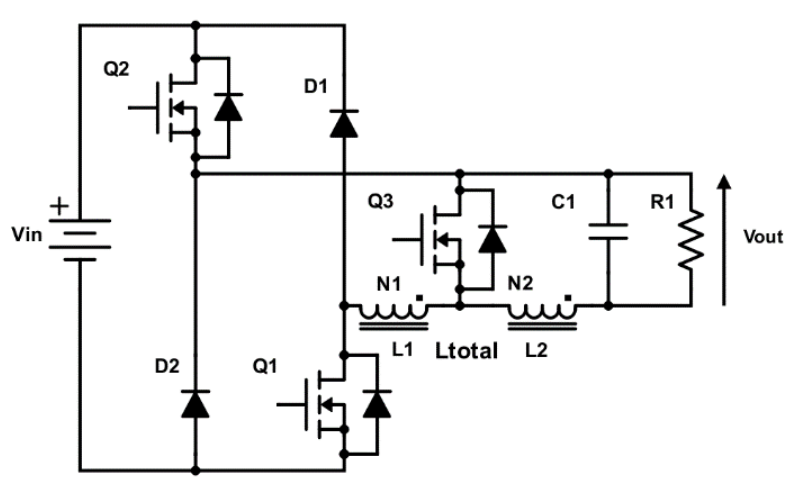

Fig .2 Asymmetric half-bridge coupled-inductor circuit.

In full-bridge or asymmetric half-bridge converters, the leakage energy is recirculated to the DC supply of the primary winding and the voltage across the switching devices is clamped to the DC supply voltage. However, two switching devices are required and there are therefore two device voltage drops in series in the primary current path.

1. Simulation of the Asymmetric Half-bridge

Fig. 3. shows simulation results for the asymmetric half-bridge coupled-inductor circuit in Fig. 2, where $V i n=200 \mathrm{~V}, \delta=16 \%, \mathrm{~N} 1: \mathrm{N} 2=10: 1, R 1=4 \mathrm{~m} \Omega$ and $C 1=6.8 \mathrm{mF}$.

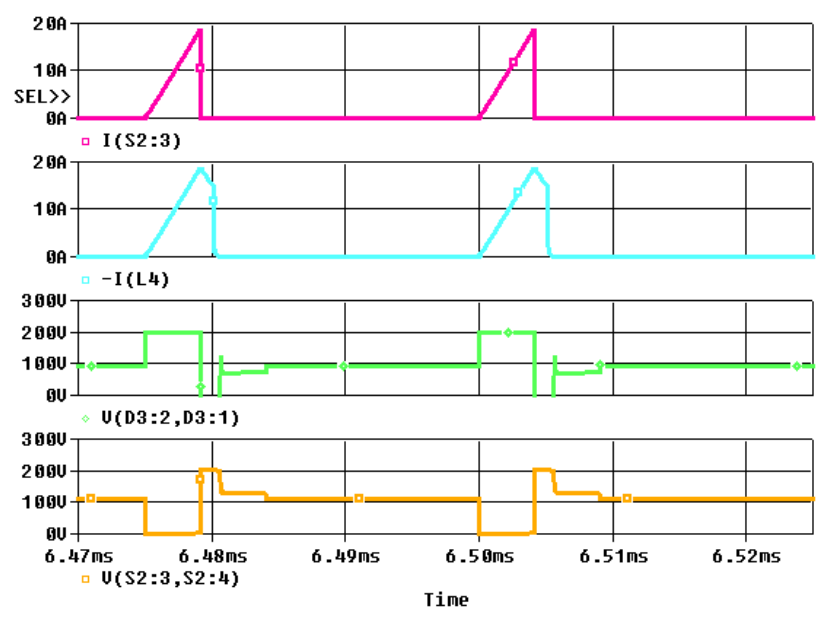

Fig .3 Simulated switching waveforms of the asymmetrical half bridge coupled-inductor buck converter.

\section{SINGLE-ENDED CONVERTER WITH VOLTAGE CLAMP CIRCUIT}

A second voltage clamp circuit, Fig. 4, is proposed to protect the main switch Q1 in Fig. 1 and provide a path to manage the energy associated with the leakage flux between L1 and L2. When the main switch Q1 is turned off, the current in the primary and secondary windings of the coupled inductor flows in diode D1, charging capacitor C2. At the same time, the 
synchronous MOSFET Q3 turns on providing a lower voltage freewheel path for the current in L2. The circuit in Fig. 4 is similar to that in a previously proposed design [7], but in Fig. 4 C2 is referenced to the supply voltage which almost halves the required capacitor voltage rating. The voltage across $\mathrm{C} 2$ must be high enough to force the primary current to zero. At the end of the switching transition the current $I_{2_{\max }}$ in L2 is given by (4). The time, $t_{t r}$, taken for the transfer of energy from the primary $N_{1}$ turns to the secondary $N_{2}$ turns is given by:

$t_{t r}=\frac{L_{\text {leakage }} I_{1} \text { max }}{V_{C_{2}}-\frac{N_{1}}{N_{2}} V_{\text {out }}}$

In order for the energy to transfer from the primary L1 to the secondary $L 2$, the voltage across $C 2$ must be greater than the referred secondary voltage. A higher voltage across $\mathrm{C} 2$ leads to a shorter transfer time and reduces losses in the conductors of inductors $L 1$ and L2. A higher voltage leads to higher switching losses in the main switch. There may therefore be an optimum value for the voltage across capacitor C2 which minimizes the losses on the primary side. This will be investigated in Section 6 .

Voltage VC2 across C2 is controlled by the energy recovery switch Q2 in Fig. 4. Q2 provides a path to transfer capacitor energy to the input supply via inductor L3. An advantage of the voltage clamp is that it only activates at the controlled voltage level $\left(V_{i n}+V_{C 2}\right)$ to protect the switching devices, and at that level, recycles excess energy back to supply Vin.

An advantage of using a clamp is that current only flows into the clamp when its threshold voltage is exceeded. This contrasts with an RC snubber [8], [9] which draws current under all operating conditions, and therefore reduces circuit efficiency. Additionally, a key benefit of the voltage clamp circuit is that the voltage across switch Q1 will not rise above the designed clamp voltage regardless of the load, thus ensuring the device is always safe from over-voltage. The voltage clamp is set at a voltage which is appropriate for the switch rating.

The voltage clamp circuit maintains a constant clamp voltage regardless of load, provided the energy recovery circuit is in continuous conduction. However, the clamp voltage will drop at lower loads when the energy recovery circuit enters discontinuous conduction.

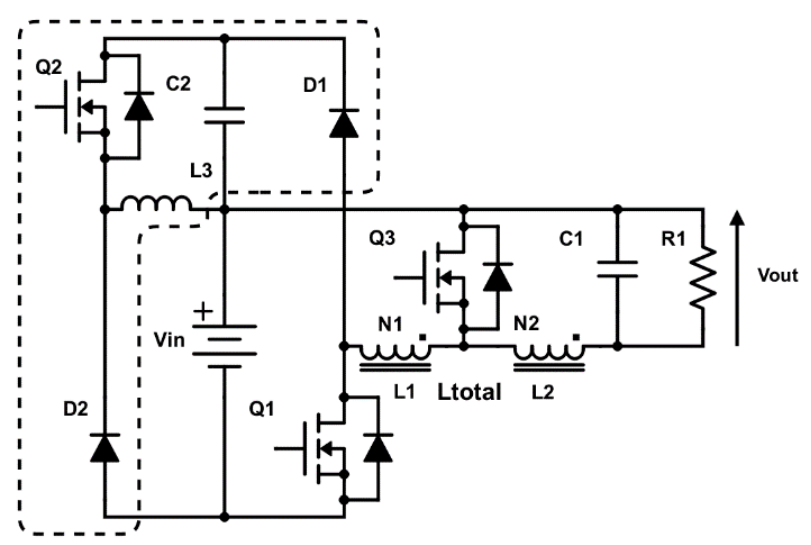

Fig .4 Voltage clamp circuit for single-ended coupled-inductor circuit. Dotted line shows the added buck converter with capacitor $\mathrm{C} 2$ referenced to $\mathrm{V}_{\text {in. }}$.

\section{Simulation of the Asymmetric Half-bridge}

Fig. 5 shows typical simulation results for the coupled-inductor circuit with voltage clamp, shown in Fig. 4, where $V_{\text {in }}=200 \mathrm{~V}, \delta_{Q 1}=16 \%, \delta_{Q 2}=13 \%$, $N_{1}: N_{2}=10: 1, \quad R_{1}=4 \mathrm{~m} \Omega, \quad C_{1}=6.8 \mathrm{mF}, \quad C_{2}=470 \mu \mathrm{F} \quad$ and $L_{3}=163 \mu \mathrm{H}$.

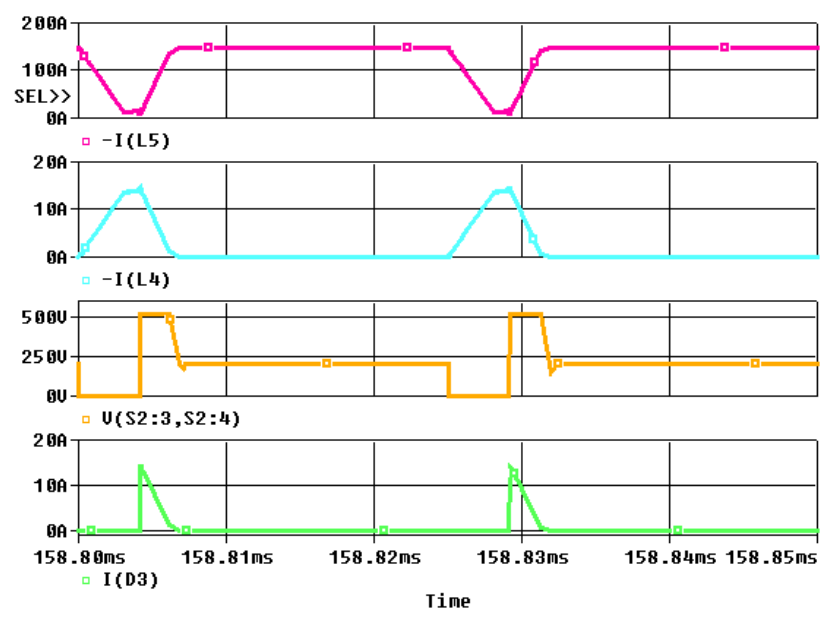

Fig .5 Simulated waveforms for coupled-inductor buck converter with a clamp voltage of $385 \mathrm{~V}$.

\section{EXPERIMENTAL RESULTS}

The main objective of the experimental study is to demonstrate that the practical circuits can achieve a high voltage step down in a single stage. At the present stage of development, the experimental setup allows for a step-down ratio of 100:1. Initial tests targeting an output voltage of $1.5 \mathrm{~V}$, requiring a duty cycle of $10 \%$, were conducted successfully. Waveforms for these tests are not presented here, but power loss data was gathered. In addition to highvoltage step-down, high-power throughput is also desirable. The circuit was then configured to operate at a maximum power throughput given the limitations of the experimental prototype. Under these operating 
conditions, where the duty cycle is $16 \%$, output voltage is $2.6 \mathrm{~V}$ and power throughput is $300 \mathrm{~W}$. Experimental results are presented for these operating conditions. Power loss data was also gathered.

Both circuits shown in Fig. 2 and Fig. 4 were experimentally assessed to evaluate switching losses and conduction losses with the same input voltage, duty cycle, and coupled inductor turns ratio. The input voltage was $150 \mathrm{~V}$ and the coupled inductor turns ratio was 10:1.

The switches were controlled via a board-mounted microcontroller to ensure minimal noise on the gates of the devices. The same PCB output stage consisting of $\mathrm{C} 1, \mathrm{R} 1, \mathrm{Q} 3$ and the coupled inductor $\mathrm{L} 1$ and $L 2$ were used for both circuits to ensure a valid comparison between both circuits. The experimental components are detailed in Table 1.

Table 1. Component for Experimental Hardware, used for Both the Asymmetric Half-bridge and Single-ended Converter.

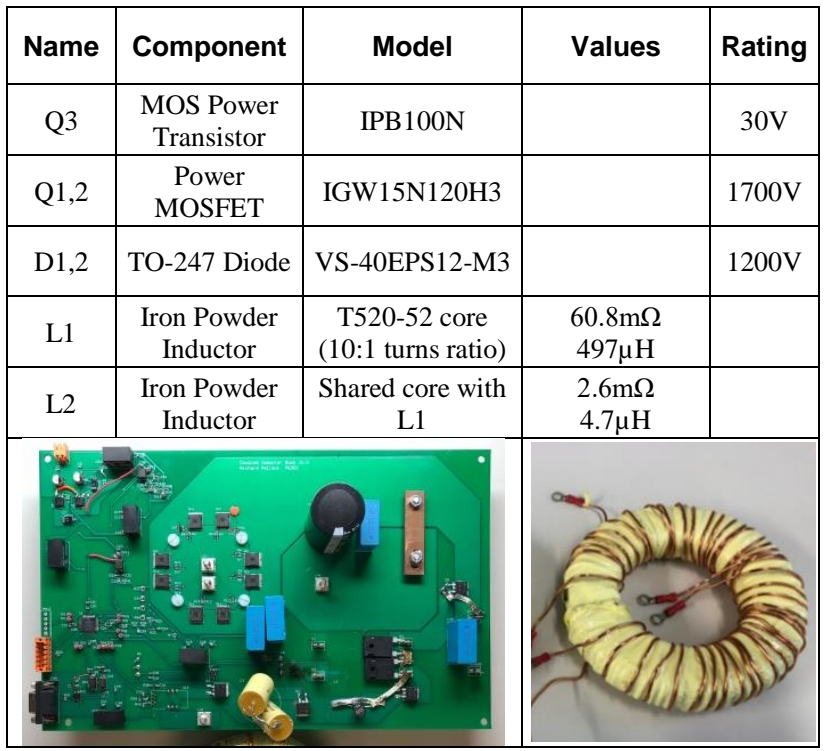

The experimental design and coupled inductor construction are also shown in Table 1. The PCB shown on the left was used for both the buck clamp snubber and later the asymmetric half bridge to ensure a fair comparison. The coupled inductor construction consisted of the primary being wound on the toroidal core with 120 turns and then two secondaries in parallel each of 12 turns wound on top of the primary turns. An additional layer of insulation was added to ensure isolation. The main design consideration of the coupled inductor is to minimise leakage inductance and maximize coupling.

As such the inductor terminations are kept as short as possible and the secondary turns are spread out to encompass as much of the core as possible.

\section{Simulation of the Asymmetric Half-bridge}

The asymmetric half-bridge with an input voltage of $150 \mathrm{~V}$ gives a change of $300 \mathrm{~V}$ (or $2 \mathrm{~V}_{\text {in }}$ ) across the coupled inductor during the switching transition of the main switch Q1. To enable a comparison, the single-ended converter also requires $300 \mathrm{~V}$ across the coupled inductor and so is controlled to have a clamp voltage of $300 \mathrm{~V}$, i.e. $\mathrm{V}_{\mathrm{C} 2}=150 \mathrm{~V}$. The conduction losses in the diodes are ignored as they only conduct for a very short period. The switching losses in the diodes are zero due to the fact the diode current falls to zero before the switch turns back on and a voltage is applied across the diode.

Fig. 6 presents results from the practical circuit configured and controlled to give an output voltage of 2.6V. From Fig. 6, it can be seen that as Q1 turns off its voltage rises from zero to $150 \mathrm{~V}$ whilst the diode voltage simultaneously falls from $150 \mathrm{~V}$ to zero and begins conducting. The voltage across the coupled inductor is the difference between the voltages across diode D2 and switch Q1. This demonstrates the 300V potential that is created across the coupled inductor in the transition period. The switch current (top trace) shows that when the switch Q1 is on all of the primary current flows through Q1. It can be assumed that Q2 conducts the same current. When switch Q1 turns off, the primary current does not fall to zero instantaneously but finds a current path through D1 and falls to zero over time. The experimental results shown are seen to follow closely those simulated in Fig. 3.

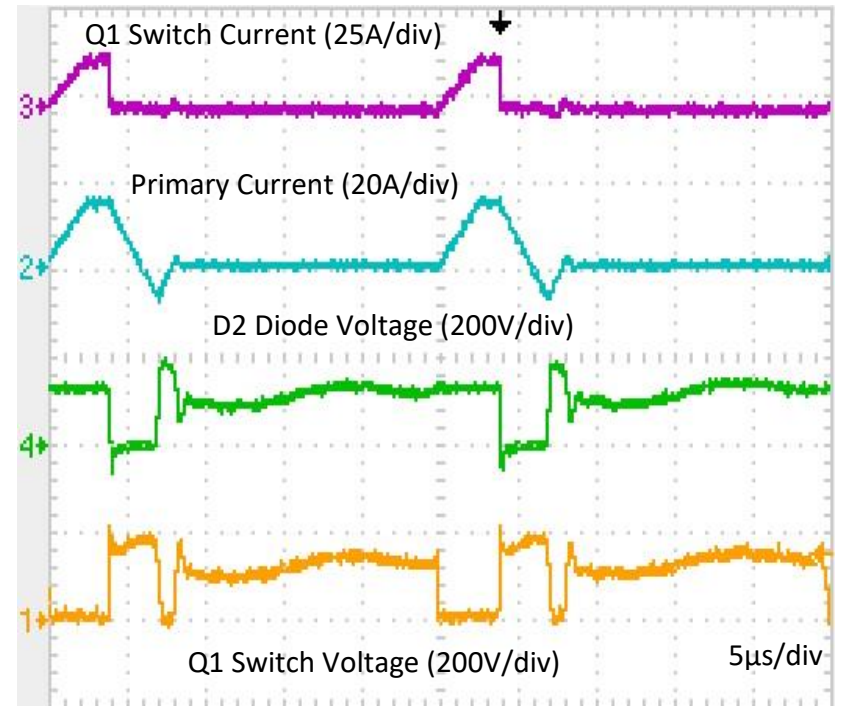

Fig .6 Switching waveforms of the asymmetrical half-bridge coupled-inductor buck converter 
Fig. 7 shows the detailed view of the turn-off waveform of Q1. This can be used to calculate the switching losses of switches Q1 and Q2. The switching losses are the product of the voltage across the switch multiplied by the current through it.

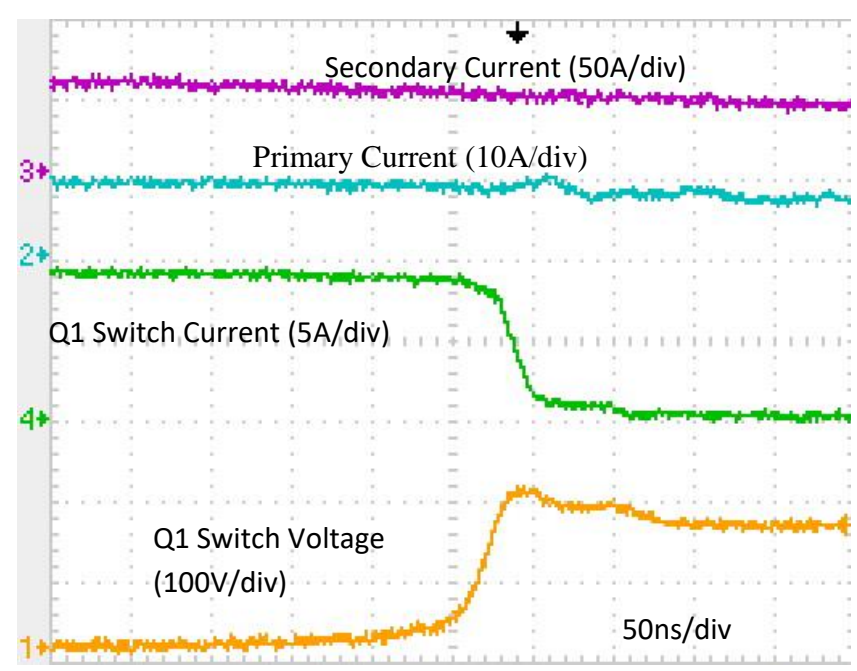

Fig .7 Detailed switching waveforms of the asymmetrical half bridge coupled-inductor buck converter.

Table 2 presents loss information for the asymmetric half-bridge coupled-inductor buck converter operated with output voltages of $1.5 \mathrm{~V}(\delta=10 \%)$ and $2.6 \mathrm{~V}(\delta=16)$. The results show that efficiency increases with power. This is due to the switching losses increasing by a smaller proportion than the increase in power. The secondary conduction loss increases approximately linearly with power and the primary loss increases fourfold.

Table 2. Asymmetrical Half-bridge Power Loss and Efficiency at $120 \mathrm{~W}$ and 300W Output.

\begin{tabular}{|l|c|c|}
\cline { 2 - 3 } \multicolumn{1}{c|}{} & $\mathbf{1 2 0 W}(\mathbf{1 . 5 V})$ & 300W (2.6V) \\
\hline Switching Loss & $10.73 \mathrm{~W}$ & $11.87 \mathrm{~W}$ \\
\hline Primary Loss & $0.43 \mathrm{~W}$ & $1.64 \mathrm{~W}$ \\
\hline Secondary Loss & $12.17 \mathrm{~W}$ & $21.30 \mathrm{~W}$ \\
\hline One Switch Conduction Loss & $3.32 \mathrm{~W}$ & $3.32 \mathrm{~W}$ \\
\hline Total Losses & $29.98 \mathrm{~W}$ & $41.46 \mathrm{~W}$ \\
\hline Percentage Efficiency & $74.05 \%$ & $84.39 \%$ \\
\hline
\end{tabular}

\section{Single-Ended Converter}

In comparison with a passive snubber, such as RC snubber, the voltage clamp proposed in Section 5 and illustrated in Fig. 4 offers switch protection and improved efficiency in a single-ended coupled-inductor converter. The voltage clamp can be controlled using the duty cycle of switch Q2 to determine the voltage of the clamp depending on the switch rating and application. The clamp circuit was tested at different voltages to assess its effect on performance and efficiency of the coupled-inductor buck converter. Readings were taken for clamp voltage varying between $250 \mathrm{~V}$ and $385 \mathrm{~V}$.

\section{A. Waveforms}

Fig. 8(a) shows the waveforms for the coupledinductor buck converter at a clamp voltage of $250 \mathrm{~V}$, and Fig. 8(b) shows the same plots but for a clamp voltage of $385 \mathrm{~V}$. By increasing the clamp voltage from $250 \mathrm{~V}$ to $385 \mathrm{~V}$, achieved by varying the duty cycle of the clamp switch Q2, the rise time of the current in the secondary decreases $5.6 \mu$ s to $2 \mu \mathrm{s}$. Thus the circuit has the design value of output current flowing in the output $\mathrm{R} 1$ for a larger percentage of the switching cycle. In each case the voltage across Q1 is clamped to the chosen clamp voltage and the switch is protected from over-voltage. During this period current flows into the clamp circuit. The experimental plots in Fig. 8(b) also confirm the simulation results in Fig. 4.

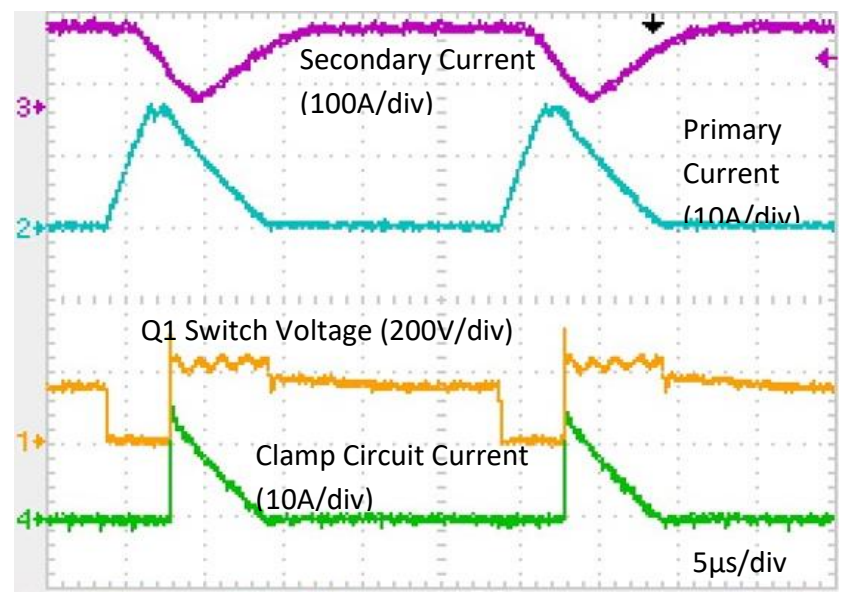

Fig .8 (a) Circuit waveforms at clamp voltage of $250 \mathrm{~V}$.

Figs. $9(\mathrm{a})$ and 9 (b) show detailed versions of Figs. 8(a) and 8 (b) focused on the on-to-off transition of the main switch Q1. These were used to calculate switching losses. 


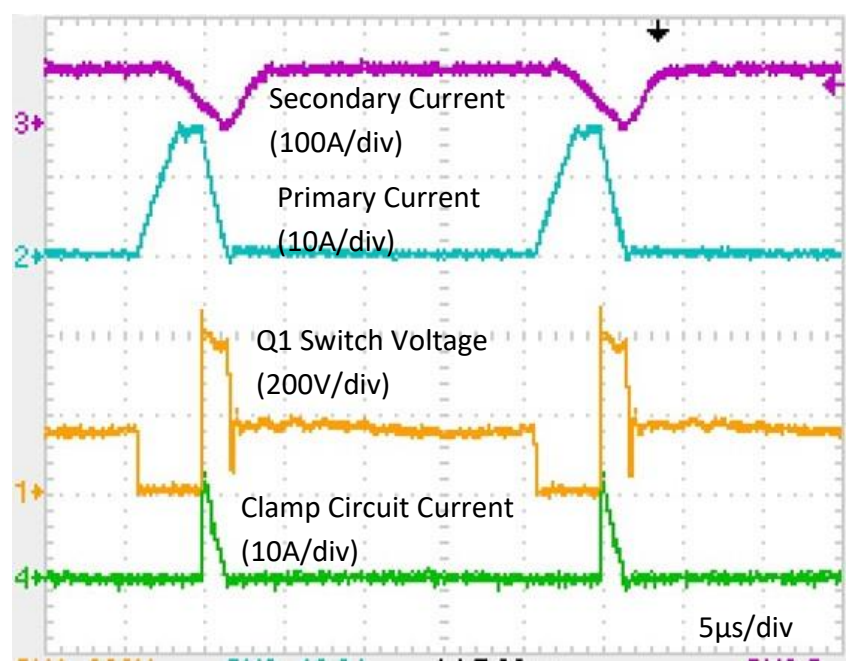

Fig .8 (b) Circuit waveforms at clamp voltage of $385 \mathrm{~V}$.

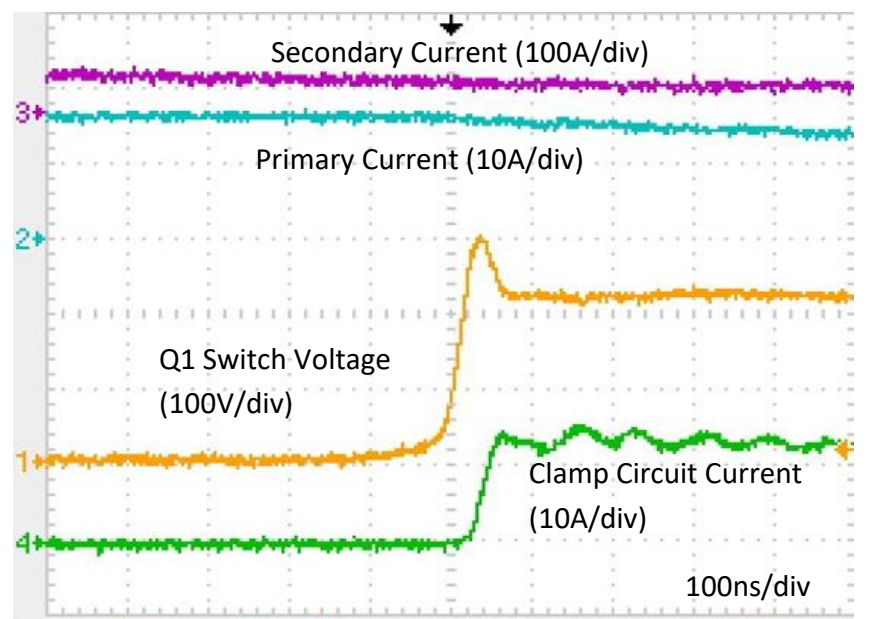

Fig .9 (a) Detailed view of circuit waveforms at clamp voltage of $250 \mathrm{~V}$

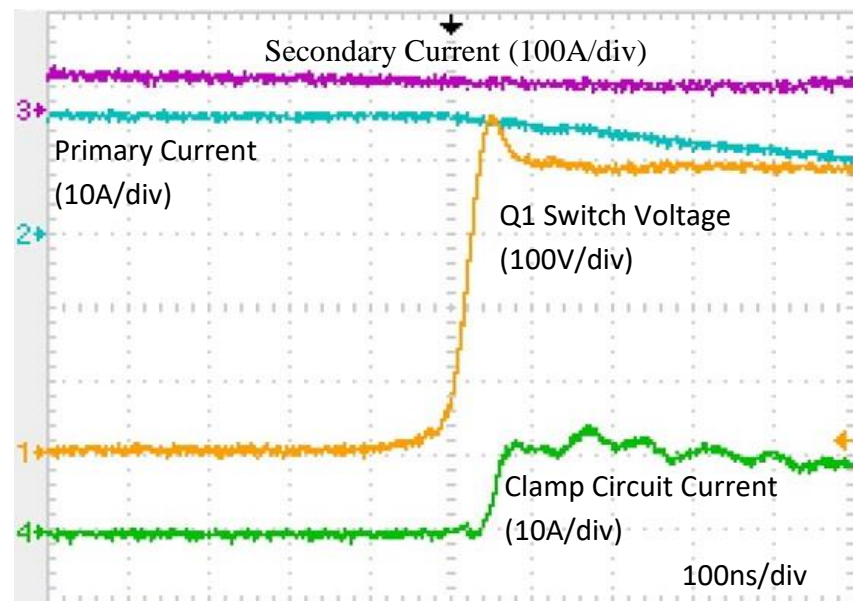

Fig .9 (b) Detailed view of circuit waveforms at clamp Voltage of $385 \mathrm{~V}$.

\section{B. Data analysis}

The clamp on the single-ended converter protects the switch from over-voltage, as shown in Figs. 8(a) and (b) where the voltage across the switch is controlled to a predefined value. Data was also collected to investigate the effect of clamp voltage variation on the efficiency of the circuit. Figs. 10(a) and (b) show the clamp current and voltage, respectively, which are used to calculate the instantaneous switching power loss shown in Fig. 10(c).

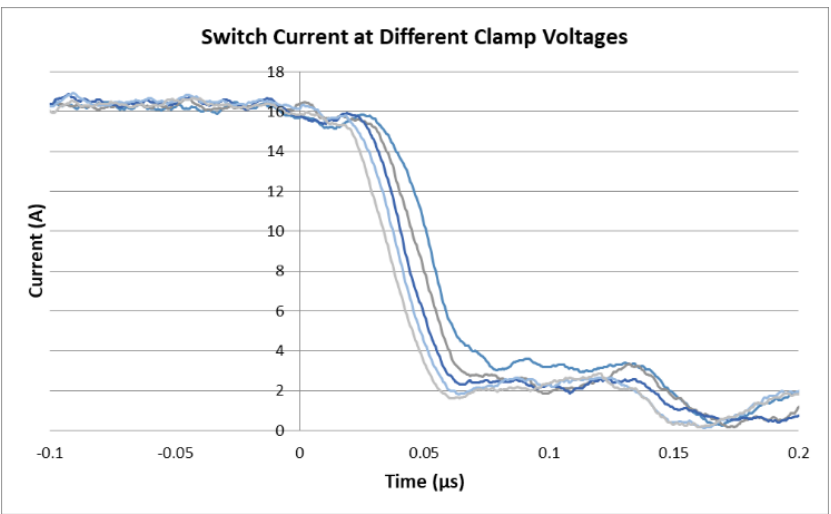

Fig .10 (a) Q1 turn off transition currents at different clamp voltages.

In Fig. 10(a), the highest clamp voltage of $385 \mathrm{~V}$ creates the current that is slowest to fall whereas the lowest clamp voltage produces the quickest fall. In Fig. 10 (b), the largest clamp voltage is $385 \mathrm{~V}$ which produces the highest voltage across the switch and a clamp voltage of $210 \mathrm{~V}$ produces the smallest voltage.

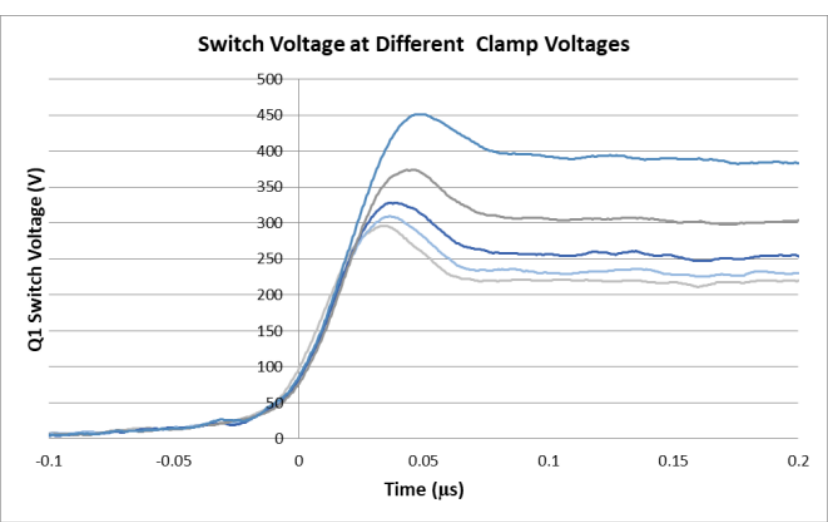

Fig .10 (b) Voltage across main switch Q1 at the turn off transition.

The results presented in Fig. 10(c) are calculated from the product of the switch voltage and current at a given time instant, for a given clamp voltage. The switching losses increase as clamp voltage is increased. This is due to the increase in current decay time as clamp 
voltage is increased. The area under each plot gives the total switching loss for one transition.

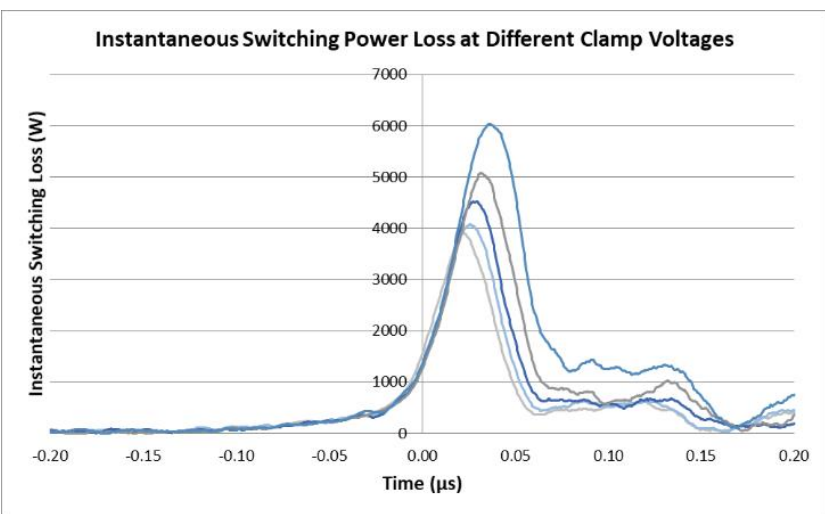

Fig .10 (c) Switching loss dependence on clamping voltage.

Fig. 11 presents a summary of all losses in the circuit and shows how they are affected by the clamp voltage. The primary side conduction losses are significantly less than those in the secondary side due to there being significantly more current in the secondary and the primary duty ratio being only $15 \%$. The switching loss on the primary side increases by $15 \mathrm{~W}$ (or $5 \%$ of input power) when the clamp voltage set-point increases from $210 \mathrm{~V}$ to $385 \mathrm{~V}$, while the conduction losses show minimal decrease. The switching losses therefore dominate the overall efficiency. The more efficient modes of operation therefore occur at lower clamp voltages.

The losses shown in Fig. 11 however, do not account for the losses within the clamp itself. A lower clamp voltage set-point means a higher current flow through the clamp. This introduces additional losses as the clamp switch will also have switching and conduction losses. Even without this data a comparison can be made.

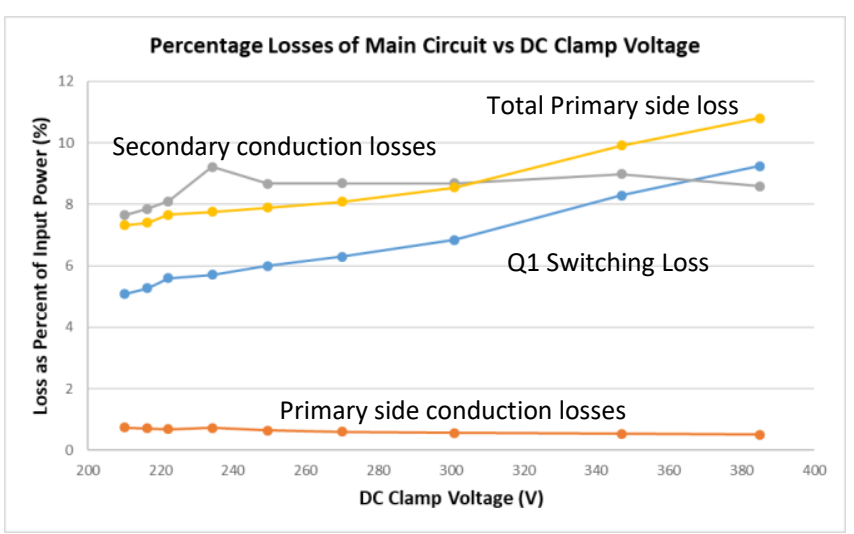

Fig .11 Summary of switching and conduction losses.

\section{Results Comparison}

As the asymmetric half-bridge converter only has a fixed voltage across the coupled inductor to create a fair comparison of its efficiency, Fig. 2, to the voltage clamp single-ended coupled-inductor converter, Fig. 4, the same supply voltage of $150 \mathrm{~V}$ as used creates a $300 \mathrm{~V}$ potential difference across the coupled inductor. This then can be fairly compared to a $300 \mathrm{~V}$ buck clamp voltage. The asymmetric half-bridge main switches (Q1 and Q2) are rated to at least $V_{\text {in }}$, whereas switch ratings of at least $V_{\text {in }}+\mathrm{VC} 2$ are required for the single-ended converter. This advantage of the asymmetric half-bridge was not utilized in these tests as the same devices were used for both to enable a fair comparison of the losses.

As shown in Fig. 12, for a $300 \mathrm{~V}$ inductor potential difference, the asymmetric half-bridge offers higher efficiencies. The comparison between both converters does not account for the losses in clamp switch Q2. These losses could however become significant at lower clamp voltages due to the increase in clamp current flowing, and if they were included in the comparison the clamp circuit efficiency would be further reduced. The comparison at $300 \mathrm{~V}$ therefore shows that the asymmetric half-bridge circuit offers better efficiency and lower rated devices.

Fig. 12 also shows that the clamp circuit efficiency is higher for clamp voltages of $210 \mathrm{~V}$ and $216 \mathrm{~V}$. At these lower clamp voltages however it is likely that the clamp losses, which are neglected here, would be proportionally greater due to higher clamp current. Additionally, the comparatively lower rated MOSFET devices that can be deployed in the asymmetrical halfbridge converter offer lower conduction losses. In combination, these two effects suggest that the asymmetrical half-bridge converter will exhibit an efficiency advantage under all operating conditions. 


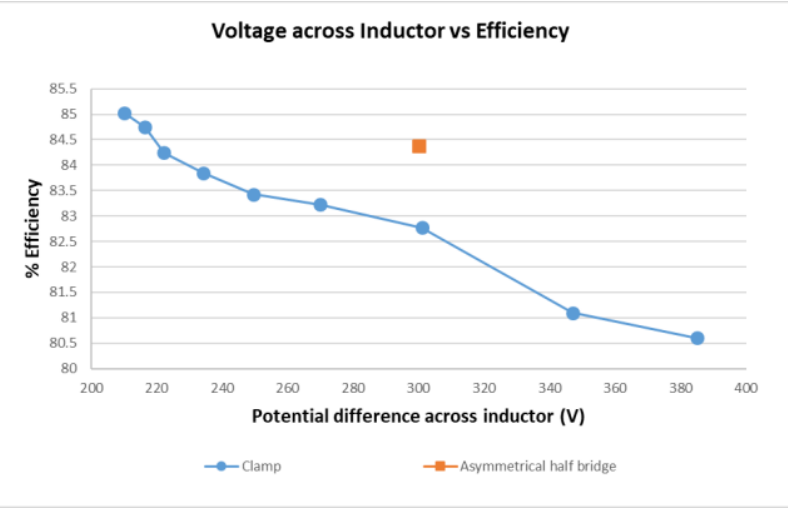

Fig .12 Asymmetrical half-bridge and single-ended voltage clamped, coupled-inductor converter efficiencies versus inductor potential difference.

The asymmetric half-bridge requires no additional control to operate, as the additional switch is controlled by the same gate signal as switch Q1 although an isolated gate driver is required for $\mathrm{Q} 2$.

A further benefit of the asymmetric half-bridge is that the four power devices in the bridge only need to be rated at $V_{\text {in }}$ whereas in the clamp both switches and additional diodes should be rated above the clamp voltage $\left(V_{i n}+V_{C 2}\right)$. The asymmetrical half-bridge coupled-inductor converter utilizes diode clamping to protect the switches and create the required voltage across the coupled inductor.

A desalination plant would be powered by a rectified three-phase AC supply creating a DC supply voltage $V_{\text {in }}$ of just under $600 \mathrm{~V}$. The asymmetrical half-bridge converter can therefore utilize $800 \mathrm{~V}$ devices whereas the single-ended converter would require $1200 \mathrm{~V}$, or even $1700 \mathrm{~V}$, rated devices.

\section{CONCLUSION}

A novel asymmetric half-bridge coupled-inductor buck converter circuit was compared with a single-ended coupled-inductor buck converter with a voltage clamp. The results presented show that the asymmetrical halfbridge converter provides an efficient circuit to drive the coupled-inductor buck converter. The leakage energy of the primary winding was managed within the bridge avoiding the need for a snubber circuit. Both switches are rated at just above the input supply voltage. Using the asymmetrical half-bridge to drive a coupled-inductor buck converter requires only one control signal as both switches on the primary side are switched simultaneously.
The single-switch coupled-inductor converter has the benefit of a single switch in the main forward path but needs an additional clamp circuit to control the voltage induced by the leakage inductance of the coupled inductor. This introduces the comparative disadvantage of requiring separate control for the duty cycle of the clamp switch.

Whilst the investigation has shown that lower clamp voltages can offer an efficiency advantage when compared to the asymmetric half-bridge circuit, full consideration of the clamp losses together with the efficiency advantages offered by lower rated MOSFET devices suggest that the asymmetric half-bridge circuit will always exhibit better efficiency. In the desalination application, the high turns ratio between primary and secondary increases the leakage inductance. The asymmetric half-bridge offers the most robust solution and highest efficiency because the leakage energy is recovered, and the switch voltages are clamped to within the voltage rating of the bridge.

\section{REFERENCES}

[1] F. A. AlMarzooqi, A. A. Al Ghaferi, I. Saadat and N. Hilal. "Application of capacitive deionisation in water desalination: A review," Desalination, vol. 342, pp. 3-15, 2014.

[2] T. J. Welgemoed and C. F. Schutte. "Capacitive deionization technologyTM: An alternative desalination solution," Desalination, vol. 183, no. 1-3, pp. 327-340, 2005.

[3] R. C. Pollock, N. McNeill, D. Holliday and B. W. Williams. "DC-DC converter with a high step-down ratio for water desalination applications," in IET PEMD Power Electronics Machines \& Drives, Liverpool, pp. 1-6, 2018.

[4] T. Chen, S. Member, C. Chen and S. Member. "Characterization of asymmetrical half bridge flyback converter," in IEEE 33rd Annual IEEE Power Electronics Specialists Conference., 2002, vol. IEEE 33rd, pp. 1-6.

[5] D. Skendzic. "Two transistor flyback converter design for EMI control," in IEEE International Symposium on Electromagnetic Compatibility, .21-23 Aug, 1990, pp.130-133.

[6] M. A. Pagliosa, T. B. Lazzarin and I. Barbi. "Output 
characteristics of two-switch flyback including the leakage inductance," in 2015 IEEE 13th Brazilian Power Electronics Conference and 1st Southern Power Electronics Conference (COBEP/SPEC), 2015, no. 13th, pp.1-5.

[7] T. Wu, T. Chen, Y. Chang and C. Chang. "Bidirectional converter with buck/forward active clamp," in International Conference on Power Electronics and Drive Systems (PEDS), 2009, pp.1-6.

[8] A. Ferraro. "An overview of low-loss snubber technology for transistor converters," in 1982 IEEE Power Electronics Specialists conference, 1982, pp.466-477.

[9] S. J. Finney, B. W. Williams and T. C. Green. "RCD snubber revisited," IEEE Trans. Ind. Appl., vol. 32, no. 1, pp. 155-160, 1996. 